$$
\begin{aligned}
& \text { CLNF- } 840408-6 \\
& \text { UCRL- } 89843 \\
& \text { PREPRINT }
\end{aligned}
$$

UCRI $--898 \triangle 3$

DE84 008943

\title{
RADIONUCLIDES IN PLANKTON FROM \\ THE SOUTH PACIFIC BASIN
}

Kenneth V. Marsh

Robert $W$. Buddemeier

This paper was prepared for submittal to American Nuclear Society

Fifth International Conference on Nuclear Methods in Environmental

and Energy Research

Mayaguez, Puerto Rico

April 2-6, 1984

March 23, 1984

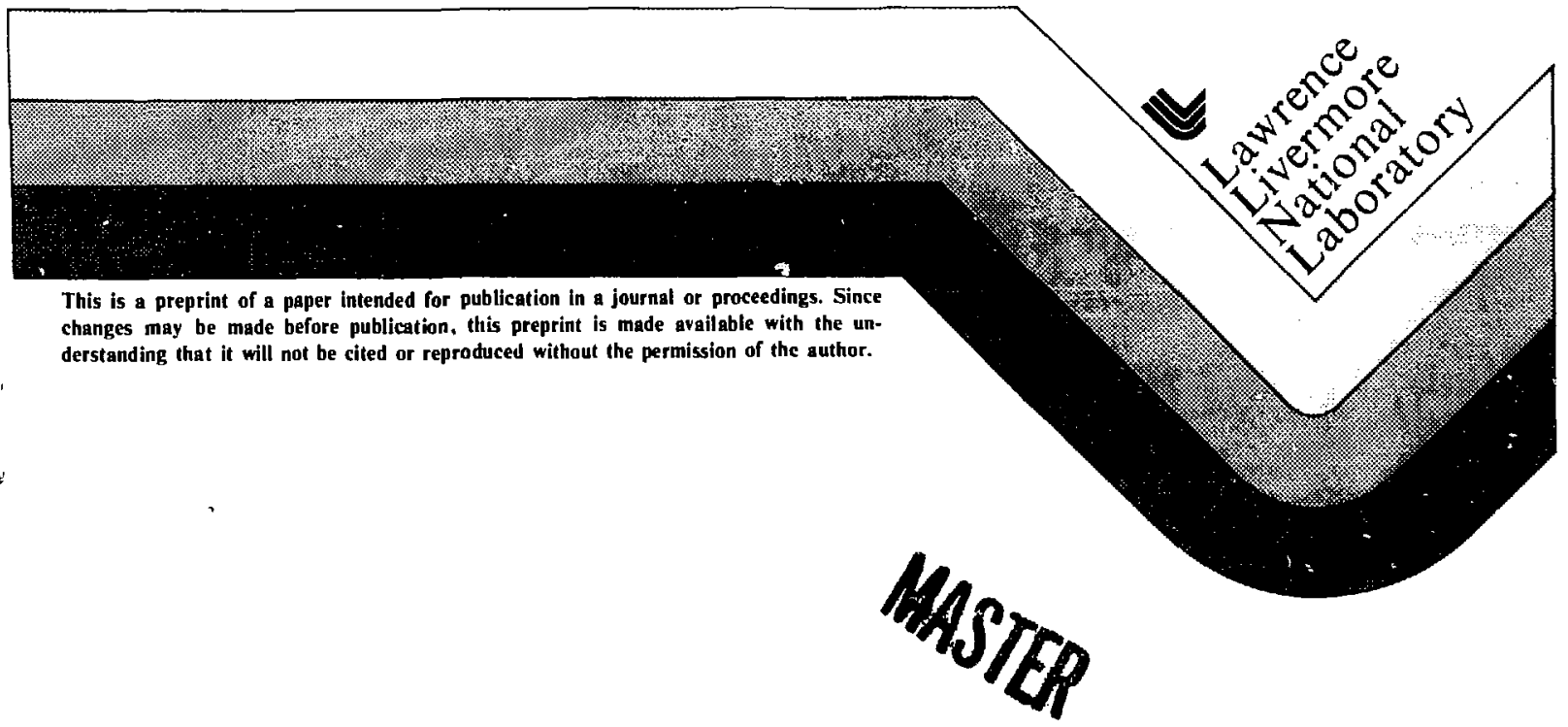

OISTAIBUTIOK OF THIS DOCUMEUT IS IWLHMTED 


\section{DISCLAIMER}

This report was prepared as an account of work sponsored by an agency of the United States Government. Neitner the United States Government nor any agency thereof, nor any of their employees, makes any warranty, express or implied. or assumes any legal liability or responsibility for the accuracy, completeness, or usefulness of any information, apparatus, product, or process disclosed, or represents that its use would not infringe privately owned rights. Reference herein to any specific commercial product, process, or service by trade name, trademark, manufacturer, or otherwise does not necessarily colistitute or imply its endorsement, recommendation, or favoring by the United States Government or any agency thereor. The views and opinions of authors expressed herein do not necessarily state or reflect those of the United States Government or any agency thereof. 


\author{
RADIONUCLIDES IN PLANKTON FROM THE SOUTH PACIFIC BASIN \\ Kenneth V. Marsh and Robert $w$. Buddemeier \\ Lawrence Livermore National Laboratory \\ P. O. Box 808 \\ Livermore, CA 94550
}

\begin{abstract}
We have initiated an investigation of the utility of marine plankton as bioconcentrating samplers of low-level marine radioactivity in the southern hemisphere. A literature review has shown that both freshwater and marine plankton have trace element and radionuclide concentration factors (relative to water) of up to $10^{4}$. In 1956 and 1958 considerable work was done on the accumulation and distribution of a variety of $f$ ission and activation products produced by nuclear tests in the Marshall Islands. Since then, studies have largely been confined to a few radionuclides, and most of the work in the last twenty years has been done in the northern hemisfiere. We participated in Operations Deepfreeze 1981 and 1982, collecting a total of 48 plankton samples from the U.S.C.G.C. Glacier on its Antarctic cruises. Battelle Pacific Northwest Laboratories sampled air, water, rain, and fallout. We were able to measure concentrations in plankton of the naturally-occurring radionuclides $7 \mathrm{Be}, 40 \mathrm{~K}$, and the $\mathrm{U}$ and $\mathrm{Th}$ series, and we believe that we have detected low levels of $144 \mathrm{Ce}$ and $95 \mathrm{Nb}$ in seven samples ranging as far south as $68^{\circ}$. Biological identification of the plankton suggests a possible correlation between radionuclide concentration and the protozoa content of the samples.
\end{abstract}

\title{
INTRODUCTION
}

Atmospheric nuclear tests, reactor operations and waste disposal programs have injected significant quantities of radionuclides into the marine environment of the

*This work was performed under the auspices of the U. $S$. Department of Energy by the Lawrence Livermore National Laboratory under Contract W-7405-Eng-48. 
northern hemisphere. These releases have, in general, been documented and considerable research has been done to characterize the fate of this radioactivity. The most extensive previous work on radionuclides in plankton was done during the nuclear tests at the Pacific Proving Grounds in 1956 and $1958^{1-5}$.

The southern hemisphere has been generally free of radionuclide input with the exception of the nuclear tests in the Tuamotus and some relatively small discharges from nuclear power plants. Very little sampling of the marine environment has been done, especially in the open ocean, and only a few studies of atmospheric radionuclide concentrations, principally at Antarctica, have been carried out. Since the southern hemisphere is nearly all ocean, any radionuclides that are released will be likely to find their way into the marine environment. While the fate of large releases could possibly be predicted by computer models of atmospheric or oceanic tranport in time for concentrated samples to be collected, chronic low-level sources cannot be so characterized and their contribution to the marine environment is not predictable. Fortunately, marine plankton, especially the phytoplankton, are particularly sensitive monitors of most anthropogenic radionuclides, having concentration factors of several hundred to several thousand for many elements. They are excellent indicators of radioactive contamination although truly quantitative measurements are difficult because concentration and separation factors are not well known and are probably quite variable.

Analysis of plankton has several advantages over other types of marine samples. The referenced work in the Pacific Proving Grounds has shown that uptake of radioactivity is rapid relative to dispersal and dilution, and once it has occurred, recycling keeps the radionuclides in the biotic layers and retards losses. These processes assure us that the plankton trace a particular water mass, a fact conEirmed by the great distances over which they were followed in the Pacific Ocean.2 Reported concentration factors 4 indicate plankton sampling provides a detection capability equivalent to $0.01-0.1$ pCi per liter of sea water for most radionuclides. As a practical matter, we can collect plankton anywhere a ship can go by utilizing inexpensive equipment and simple techniques. The final samples are easily transported, stored and analyzed.

The principal disadvantage of plankton analysis is that calibration sufficiently reliable to permit calculation of water concentrations is very difficult. While some attempts have been made and procedures suggested for calibration, 6,7 concentration factors depend on such uncontrollable parameters as species composition, growth stages, and 
bioavailability. Isotopic ratio measurements, however, should be accurate, especially in samples of approximately the same age. In some cases merely the detection of unusual or short-lived nuclides would be valuable information.

\section{SAMPLE COLLECITION}

We collected plankton in the austral summers of 1981 and 1982 on board the U. S. Coast Guard Cutter Glacier along the cruise tracks shown in Fig. 1. Personnel from Battelle Pacific Northwest Laboratories organized our portion of the cruises and collected the samples. They also collected air filter, dry-fallout, rainwater, and large volume sea water samples. On the first cruise, piankton was collected by pumping water at a rate of $250 \mathrm{gal} / \mathrm{min}$ through the ship's fire mains into a $158 \mu \mathrm{m}$ plankton net suspended in a $55 \mathrm{gal}$. drum. On the second cruise, some samples were collected by pumping, others by a variety of nets towed behind the ship. Samples were preserved in $5 \%$ buffered formalin for shipment, and a $25 \mathrm{ml}$ subsample was taken for biological analysis.

Dr. Wim Kimmerer of the University of Hawaii Institute of Marine Biology performed the biological analyses on eleven samples; Professor John Wormurh of Texas A\&M University analyzed the remainder. Generally, they first counted large organisms in the entire sample and then took aliquots by means of Nytex screens or a plankton splitter and counted smaller species under the microscope.

For the radionuclide measurements, the samples; were drained on a Nytex screen, weighed wet (weight range: 25$400 \mathrm{~g}, 200 \mathrm{~g}$ average), recombined with the liquid, dried at $110^{\circ} \mathrm{C}$, ground and packed into standard-geometry containers for $\gamma$-spectrometry. All samples were counted on our low-background Compton-suppressed spectrometer for at least $10^{4} \mathrm{~min}$. The resulting spectra were computer analyzed and results expressed as pci/gram wet, decay corrected to a common date. Detection limits, based on counter background in appropriate energy regions, were calculated for several radionuclides and are given in Table II. These limits are quite variable and depend on concentrations of other radionuclides in the sample, sample weights, counting geometry and radioactive-decay factors.

\section{RESULTS AND DISCUSSION}

The concentrations of ${ }^{7} \mathrm{Be},{ }^{95} \mathrm{Nb}$ and $144 \mathrm{Ce}$ in plankton are listed in Table I and plotted along with Battelle's air filter data in Figs. 2-5. $7 \mathrm{Be}$ is produced by spallation reactions of cosmic rays on atmospheric constituents at high altitudes and is a well-known component of atmospheric radioactivity. The higher levels measured in the air filters are reflected in the plankton, and from Battelle's filtered 


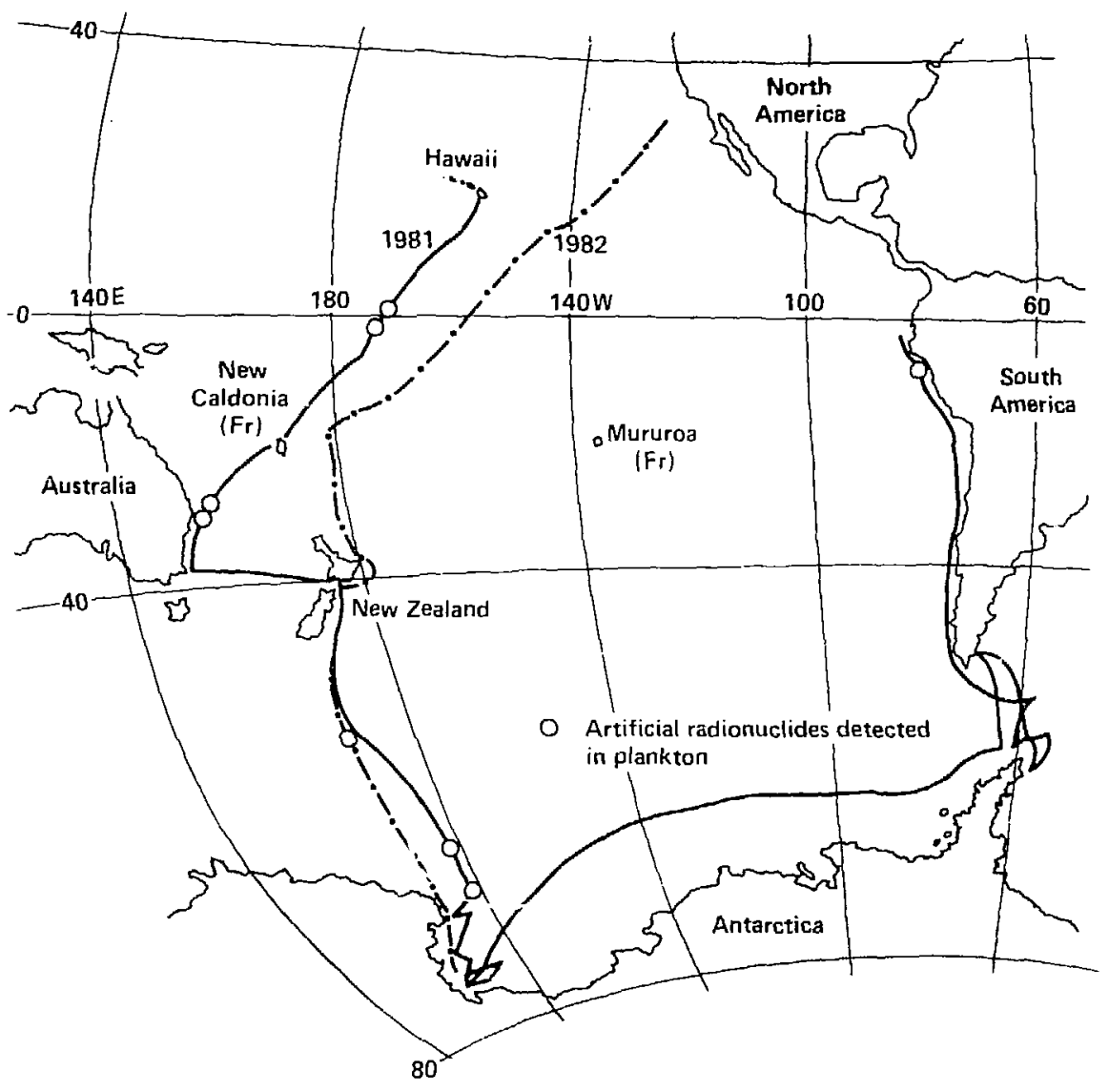

Fig. 1: 1981 and 1982 Cruise Tracks. 
TABLE I. Radionuclides Detected in Plankton*

\begin{tabular}{|c|c|c|c|c|c|}
\hline Cruise & ${ }^{7} \mathrm{Be}^{\dagger}$ & $95 \mathrm{NL}^{+}$ & $144 \mathrm{Ce}^{\dagger}$ & ${ }^{\circ} \mathrm{Lat}$ & ${ }^{\circ}$ Long. \\
\hline 1981 & -- & $30.6 \pm 26$ & $107 \pm 42$ & $3 N$ & $177 w$ \\
\hline 1981 & $\cdots$ & $16.4 \pm 56$ & $-=$ & 45 & $84 \mathrm{~W}$ \\
\hline 1981 & $174 \pm 35$ & $7.06 \mp 35$ & $36.4 \pm 60$ & $6 s$ & $177 \mathrm{E}$ \\
\hline 1982 & $224 \pm 42$ & $-\overline{-}$ & -- & 185 & $178 \mathrm{E}$ \\
\hline 1981 & $\overline{-}$ & --- & $32.4 \pm 28$ & $26 s$ & $158 \mathrm{E}$ \\
\hline 1981 & $368+14$ & $5.34+68$ & --- & 285 & $154 \mathrm{E}$ \\
\hline 1982 & $105 \mp 38$ & $-\overline{-}$ & -- & 305 & $178 \mathrm{E}$ \\
\hline 1981 & $360 \mp 20$ & -- & -- & $32 \mathrm{~s}$ & $152 \mathrm{E}$ \\
\hline 1981 & $275 \pm 14$ & - & -- & $35 \mathrm{~s}$ & $156 \mathrm{E}$ \\
\hline 1981 & $149 \mp 44$ & -- & -- & 365 & $159 E$ \\
\hline 1981 & $292 \mp 13$ & -- & -- & 375 & $161 E$ \\
\hline 1981 & $450 \mp 17$ & -- & -- & 395 & $168 \mathrm{E}$ \\
\hline 1982 & $188 \mp 43$ & - & -- & 395 & $178 \mathrm{E}$ \\
\hline 1982 & $55 . \overline{7} \pm 36$ & -- & -- & 535 & $169 \mathrm{E}$ \\
\hline 1982 & $47.0 \mp 33$ & $3.3 \pm 46$ & -- & $58 \mathrm{~s}$ & $170 \mathrm{E}$ \\
\hline 1982 & $34 \cdot 3 \pm 23$ & $\bar{E}$ & -- & 625 & $170 \mathrm{E}$ \\
\hline 1981 & -- & $2.33+29$ & $28.6+16$ & 655 & $178 \mathrm{E}$ \\
\hline 1981 & -- & $18.1 \pm 18$ & $106+8$ & 685 & $180 \mathrm{E}$ \\
\hline 1982 & $847 \pm 34$ & $-\pi$ & $-\overline{-}$ & $72 \mathrm{~S}$ & $170 \mathrm{E}$ \\
\hline 1982 & $88 \cdot \overline{0}+16$ & -- & -- & 735 & $170 \mathrm{E}$ \\
\hline 1922 & $200+29$ & -- & -- & $77 \mathrm{~S}$ & $167 \mathrm{E}$ \\
\hline
\end{tabular}

* Units are femto Curies per gram of wet plankton. Errors are one sigma percent.

$40 \mathrm{~K}$ was detected in all samples with an average value of $1660+668$.

$226 \mathrm{Ra}$ was detected in 12 samples with an average value of $37.0+2008$.

$238 \mathrm{U}$ was detected in $\$ 0$ samples with an average value of 372 +1508 .

235 U was detected in 10 samples with the average activity $238 \mathrm{U} / 235 \mathrm{U}$ of $22.3 \pm 208$. (Natural U is 21.8 )

† Average upper limit values for all other stations are included in Table II.

TABLE II. Upper Limit Concentrations

for Selected Radionuclides in Plankton*

femto Curies/gram wet plankton

\begin{tabular}{ccccccc}
\hline $7_{\mathrm{Be}}$ & $54 \mathrm{Mn}$ & $65_{\mathrm{Zn}}$ & $95_{\mathrm{Nb}}$ & $103_{\mathrm{Ru}}$ & $144 \mathrm{Ce}$ & $241_{\mathrm{Am}}$ \\
\hline 442 & 2 & 4 & 20 & 500 & 16 & 10
\end{tabular}

*Averaged over all stations. The upper limit concentration range for each nuclide is approximately a Eactor of three. 


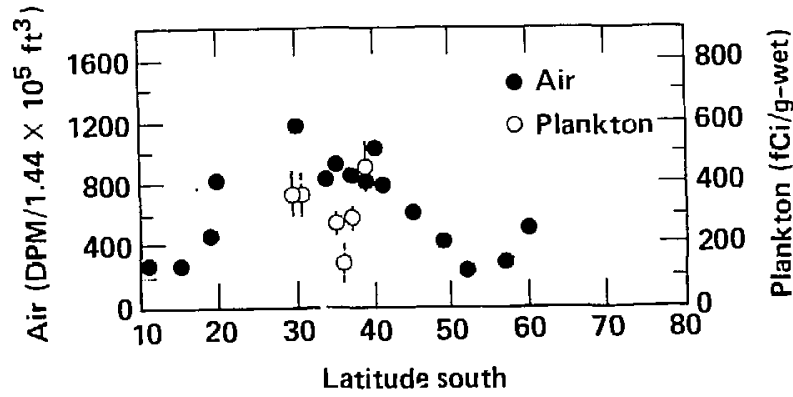

Fig. 2: ${ }^{7}$ Be Concentrations 1981. Error bars are $1 \sigma$ counting error (not available for air).

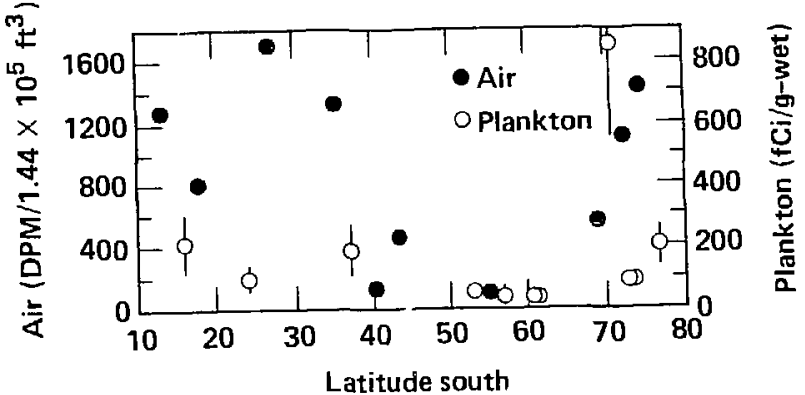

Fig. 3: 7Be Concentrations 19்2. Error bars are 10 counting error (not available for air). 


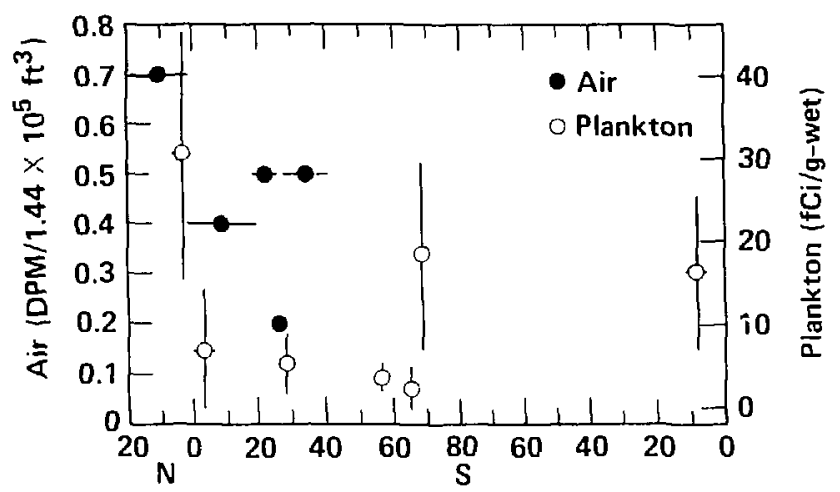

Route south Degrees of latitude Route north

Fig. 4: $95 \mathrm{Nb}$ concentrations in latitude bands, 1981 and 1982. Horizontal bars indicate distance covered during collection. Vertical errors are lo counting error (not available for air).

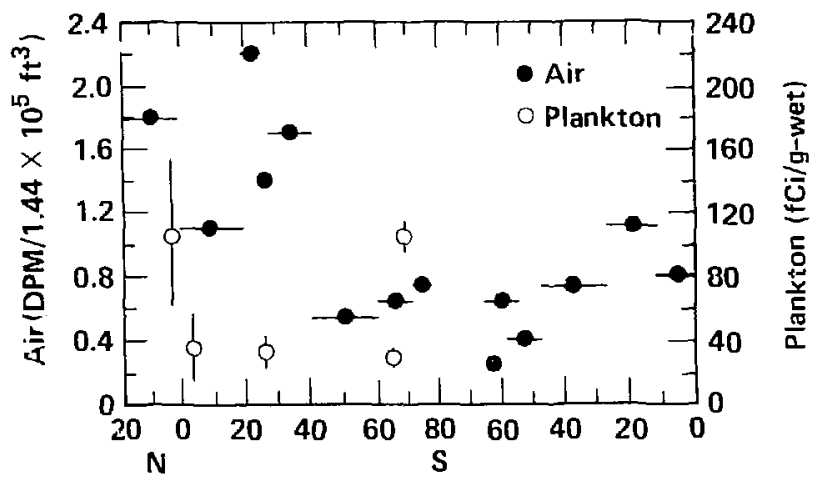

Route south Degrees of latitude Route north

Fig. 5: $\quad{ }^{144} \mathrm{Ce}$ concentrations in latitude bands, 1981. None detected in 1982. Horizontal bars indicate distance rovered during collection. Vertical error bacs are lo counting error (not available for air). 
sea water analysis we calculate a concentration factor in plankton of $2770 \pm 1200$, in the range generally observed for these factors. We were not able to. calculate concentration factors for $95 \mathrm{Nb}$ and $144 \mathrm{Ce}$, as both these nuclides were associated with the sea water particulate and were below detection limits in the filtrate. While there are possible interferences from $214 \mathrm{~Pb}-214 \mathrm{Bi}$ and $228 \mathrm{Ac}-228 \mathrm{Th}$ in the identificarion of ${ }^{95} \mathrm{Nb}$ and $144 \mathrm{Ce}$, we feel these have been properly taken into account. The fact that these nuclides were also detected independently by Battelle in the air and sea water particulate and are known to have very large concentration factors in plankton ${ }^{-4}$ lead us to believe that their identification is correct. As in the case of the ${ }^{7} \mathrm{Be}$, the higher levels of $95 \mathrm{Nb}$ and $144 \mathrm{Ce}$ in the plankton are associated with those in the air filters. We measured concentration factors relative to average sea water of 600 for $\mathrm{U}$ (range 100-1000) and 3-4 for $\mathrm{K}$.

The biological analyses show our samples to be representative of marine plankton from the latitudes where they were collected. $95 \mathrm{Nb}$ and $144 \mathrm{Ce}$ seem to be associated with samples in which foraminifera comprise a major fraction of the biomass. The high levels of $7 \mathrm{Be}$ observed in the 1982 samples from $72^{\circ} \mathrm{S} 170^{\circ} \mathrm{E}$ and $77^{\circ} \mathrm{S} 167^{\circ} \mathrm{E}$ are probably due to the fact that these samples are composed almost entirely of centric diatoms. These samples also showed a factor of ten excess $234 \mathrm{Th}$ over its parent $238 \mathrm{U}$. While factors other than species composition are important to bioconcentration, a generally higher specific activity of smaller organisms has been reported. 4

We have found plankton easy to collect and analyze. concentrations of naturally occurring radionuclides have no significant effect on our abilitity to detect low levels of artificial radionuclides. We believe we have found $95 \mathrm{Nb}$ and $144 \mathrm{Ce}$ in several samples but, other than to note that these are common, high-yield fission products with very large concentration factors and the concentrations we observed were very low, we do not know their origin. $95 \mathrm{Nb}$, $144 \mathrm{Ce}$ and higher levels of $7 \mathrm{Be}$ seem to be associated with the presence of unicellular organisms.

\section{ACENOWLEDGMENTS}

We wish to express oux thanks to Dr. Ned Wogman and his group at Battelle Pacific Northwest Laboratory for their assistance in procuring the space on the Glacier, for collecting the samples at sea, and for allowing us to use their data prior to publication.

This work is supported by the U. S. Department of Energy, Division of International Security Affairs. 
1. L. K. Donaldson, A. H. Seymour, E. E. Held, N. O. Hines, F. G. Lowman, P. R. Olson, A. D. Welandei, Survey of Radioactivity in the Sea Near Bikini and Eniwe tok Atolls, June 11-21, 1956, Applied Fisheries Laboratory: University of Washington, Seattle, Washington, UWFL-46 (1956).

2. J. H. Haley, Ed., Operation Troll, Health and Safety Laboratory, U. S. Atnmic Energy Commission, New York Operations office, NYO-4656 (1956).

3. A. H. Seymour, E. E. Held, F. G. Lowman, J. R. Donaldson, D. J. South, Survey of Radioactivity in the Sea and in Pelagic Marine Life West of the Marshall Islands, September 1-20, 1956, Applied Fisheries Laboratory, University of Washington, Seattle, washing ton, UWEL-47 (1957).

4. F. G. Lowman, Radionuc'ides in Plankton Near the Marshall Islands, 1956, Laboratory of Radiation Biology, University of Washington, Seattle, Washington, UWFL-54 (1958).

5. N. O. Hines, Proving Ground An Account of the radiobiological studies in the Pacific, 1946-1961 (University of Washington Press, Seattle, 1962).

6. J. E. Portmann, Ed., Manual of Methods in Aguatic Environment Research, Part 2 - Guidelines for the Use of Biological Accumulators in Marine Pollution Monitoring, Food $i$ ?d Agriculture Organization of the United Nations: United Nations Environment Programme, FAO Fisheries Technical Paper No. 150 (1976).

7. T. A. Jenckes, The Feasibility of Using Phytoplankton in a Quantitative Method of Detecting Low Levels of Fadionuclides, Ph.D. Thesis, Temple University, Philadelphia, PA (1975). 